\title{
Derechos económicos y sociales y transformación productiva con equidad en América Latina y El Caribe
}

\author{
CEPAL
}

\section{I) Introducclón}

La presente nota responde a la invitación del Secretario General de la Conferencia Mundial de Derechos Humanos a la Comisión Económica para América Latina y El Caribe (CEPAL) para contribuir a la reflexión sobre las dimensiones económicas y sociales de los derechos humanos con vislas a la celebración de la Conferencia Mundial de Derechos Humanos a realizarse en Viena, Austria en el mes de junio de 1993.

La Reunión Regional para América Latina y El Caribe de la Conterencia Mundial de Derechos Humanos realizada en San José, Costa Rica del 18 al 22 de enero de 1993 resaltó en su declaración tinal que “...la inlerdependencia e indivisibilidad de los derechos civiles y politicos, económicos, sociales y culturales son fundamentales para el examen del tema de los derechos humanos y en consecuencia no se puede ni se debe desconocer el goce de unos sopretextos de no haberse alcanzado el pleno distrute de los otros."

Así mismo, sefaló que "...el derecho al desarrollo es un derecho humano inalienable, como se establece en la Declaración sobre el derecho al Desarrollo, aprobada por la Asamblea General en su resolución 41/128 del 4 de diciembre de 1986." Insistiendo que "La comunidad inlernacional debe tomar medidas en el menor plazo posible para hacer efectivo esle derecho mediante mecanismos adecuados que tengan en cuenta el derecho al desarrollo en un medio ambiente sano $y$ 
ecológicamente equilibrado como un derecho universal, contorme a la Declaración de rio."

Tomando en cuenta lo anteriormente sefialado la CEPAL se propone en el futuro extender su reflexión y propuestas al ámbito de los derechos humanos fundamentalmente en sus dimensiones económicas y sociales. Los planteamientos que se expondrán a conlinuación constituyen apenas un inicio de dicha reflexión.

\section{II) Derechos económlcos y soclales y transformaclón productlva con equldad}

En los instrumentos jurídicos de las Naciones Unidas, el empleo de la expresión "derechos humanos", suele cubrir no sólo los derechos de libertad individual, civiles y políticos, sino también los económicos, sociales y culturales. Sin embargo, la primera reacción del ciudadano común ante esa expresión - ya sea apelando a la deiensa o aludiendo a la violación de los derechos humanos- evoca imágenes dramáticas de tortura, desapariciones, persecución, discriminación, limilaciones a la libertad de expresión o el empleo arbitrario del poder público ante la sociedad civil.

Por eso, durante la vida inslilucional de las Naciones Unidas, ha existido cierla tensión en el manejo del tema de las libertades fundamentales de las personas y de las comunidades en relación con el tema del desarrollo económico y social. Por una parle, se ha manifestado la tendencia a separar el ámbito económico y social del político, con la idea de que la cooperación económica era la menos "conflictiva" de las dos $y$, por ende, la que más tácilmente podia atraer la cooperación internacional. Por el contrario, los esfuerzos para someter el respelo de los derechos civiles y políticos a algún régimen de cooperación internacional tendian a dividir más que a aglulinar.

Por otra parte, la Carta de las Naciones Unidas liga estrechamenle el tema de los derechos humanos a las cuestiones económicas y sociales. Asi, ya en el Preámbulo de esa Carta se resuelve: "...promover el progreso social y ... elevar el nivel de vida dentro de un concepto más amplio de la libertad..." Además, el tema como tal se trata en el Capitulo IX, titulado "Cooperación inlernacional económica y social". Finalmenle, la Comisión de Derechos Humanos eslablecida en virtud de la Carta forma parte del Consejo Económico y Social.

El estrecho vinculo entre ambos temas también se refleja en la Declaración Universal de Derechos Humanos, proclamada el 10 de diciembre de 1948, y en el Pacto Internacional de Derechos Económicos, So- 
ciales y Cullurales (1966). Este último obliga a los Estados que lo hayan ratificado a reconocer y observar una amplia gama de derechos relacionados con seguridad social, acceso al trabajo, acceso a la satisfacción de necesidades básicas $y$, en general, el derecho a un nivel de vida adecuado.

Si se acepta el criterio más amplio de derechos humanos para que éslos incluyan lo económico, social y cultural, se podría sostener que los avances aludidos en materia de democralización en los paises de la región se vieron parcialmente contrarrestados con cierlos retrocesos registrados en los últimos ańos. Así, por ejemplo, se produjo un importante aumento en la incidencia de la pobreza: en 1980, 136 millones de lalinoamericanos $-41 \%$ del tolal de la población- vivían bajo la línea de pobreza; al tinalizar el decenio, el número de personas en esa condición habia aumentado a 195 millones, es decir, más del $45 \%$ de la población. Algo análogo ocurre con la incidencia de la indigencia, que pasó del $19 \%$ al $22 \%$ entre 1980 y 1990 . En el mismo orden de ideas, la información de que se dispone sugiere que en la mayoría de los países, la de por si desigual eslructura distributiva de los años setenta tendió a empeorar durante el decenio de 1980.

Una de las interroganles que desde la perspectiva de América Latina y El Caribe demanda una urgente respuesta es cómo conciliar los avances langibles en materia de derechos civiles y políticos con los retrocesos en materia de derechos económicos y sociales. Al respecto cabría admitir que no es lo mismo evilar la violación de los derechos civiles o políticos de las personas y de las comunidades que asegurar el cumplimiento del "derecho de toda persona a un nivel de vida adecuado para sí y su familia, incluso alimentación, vestido y vivienda adecuados, y a una mejora continua de las condiciones de existencia." Lo primero cae en el dominio élico, cullural, polílico e institucional de una sociedad; to segundo influye además sobre la asignación de los recursos. Si bien los derechos politicos y civiles y los derechos económicos y sociales pueden tener estatutos juridicos diversos en cuanto a su carácler, exigibilidad y mecanismos de protección, ambos aspeclos forman parte tanto de una visión integral del desarrollo como de una visión integral de tos derechos fundamentales de las personas.

De no realizarse avances en los derechos económicos y sociales, los mismos derechos civiles y políticos tan difícilmente alcanzados tienden a Iransformarse en letra muerta para los sectores con menores

1. Artículo 11 del Pacto Internacional de Derechos Económicos, Sociales y Culturales. 
recursos y más bajos niveles de educación e información. Hoy en día está ampliamente probado que esos sectores tienen un acceso mucho más difícil a la justicia y a las posibilidades de defenderse frente a atropellos de terceros o del Estado. Pobreza y ausencia de ejercicio de ciudadanía van muchas veces de la mano. Producir un cambio en esta situación es una necesidad fundamental para estabilizar las democracias de la región y para lograr una ciudadania verdaderamente universal.

Considerando, que el desarrollo es condición necesaria para la defensa de los derechos civiles y polílicos, CEPAL se ha abocado a responder al desatío de cómo avanzar, de manera simultánea, en lograr un crecimiento ambientalmenle suslentable, con mayor equidad y en democracia. Bajo el tílulo genérico de Transformación productiva con equidad, se han elaborado un conjunlo de trabajos entre 1990 y el presente, que buscan provocar un debate esclarecedor sobre un marco de referencia coherente para el desarrollo latinoamericano y caribefio. ${ }^{2}$

El loco de este planteamiento es la transtormación productiva, sustentada en una incorporación deliberada y sislemálica del progreso técnico, con miras a lograr crecientes niveles de productividad y de generación de empleo productivo. Un desarrollo basado en el progreso técnico y que posibilite una mejor inserción internacional, conduce, a la vez, a mayores salarios, y exige una elevación del nivel educacional y de las condiciones de salud y vivienda (es decir, más y mejor capital humano), asi como también una transformación de las relaciones existenles al interior de la empresa, todo lo cual contribuye a incrementar la equidad.

Lograr esas melas exige un enfoque sistémico, medianle el cual, además de mantener equilibrios macroeconómicos y precios correctos, sea posible realizar acciones selectivas de carácter sectorial, así como innovaciones inslitucionales que permitan a los agentes económicos concerlar sus esfuerzos para conciliar la equidad y el crecimiento. En

2. CEPAL, Tranformación productiva con equidad. La tarea prioritaria del desarrollo de América Lstina y el Caribe en los años noventa (LC/G.1601-P), Santiago de Chile, marzo de 1990. Publicación de las Naciones Unidas, No de venta: S.90.Il.G.6.; CEPAL, El desarrollo sustentable: transformación productiva, equidad y medio ambiente (LC/G. 1648/Rev. 2-p), Santiago de Chile, mayo de 1991. Publicación de las Naciones Unidas, No de venta: S.91.II.G.5.; CEPAL, Equidad y transformación productiva: un enfoque integrado (LC/ G.1701 (SES.24/3) y Corr.1), Santiago de Chile, abril de 1992; CEPAL/Oficina Regional de Educación de la UNESCO para América Latina y el Caribe, Educación y conocimiento: eje de la transformación productiva con equidad (LC/G.1702 (SES.24/4) / Rev.1), Santiago de Chile, abril de 1992. 
ese enfoque sistémico, la observación de los derechos civiles y políticos de la población juega un papel se precisa un entorno de estabilidad y cohesión social en que habrá de darse el desarrollo.

Si bien es común que buena parte del pensamiento económico centre su alencion en las posibles contraposiciones entre polílicas orientadas al crecimiento y aquellas en procura de una mejor distribución del ingreso, CEPAL ha puesto el acento en la complementariedad entre estrategias y polílicas disefiadas para lograr, al mismo tiempo, crecimienlo y equidad. Si se agruparan las políticas publicas en distintas categorías, ordenadas según la compatibilidad o el antagonismo entre sus objelivos de crecimiento y de equidad, tanto a corto como a largo plazo, se vería que el grupo de las políticas con posibilidades de complementariedad es mayor que el de las contrapuestas. Este hecho es fundamental para el enfoque integrado de CEPAL.

Se sostiene así, que el crecimiento y la equidad son producto tanto de la política económica como de la social. Habria que superar la idea de que la política económica ha de apuntar a un buen crecimienlo, en tanto que corresponde a la política social centrarse en el problema de la distribución. Ni una ni otra son neutras en lérminos distributivos, y ambas inciden sobre la capacidad de crecer. Es por eso que se plantea un enloque integrado, en el que la política pública en su conjunto apoya simultáneamente la transformación productiva y la equidad. Ese enfoque integrado es igualmenle aplicable, a los derechos cívicos y políticos por una parte, y los económicos y sociales por otra.

Todo lo anterior parte de un reconocimiento de que la formulación y aplicación de estralegias y políticas económicas habrá de ocurrir en un contexlo democrático, pluralista y participativo. Eslo influye sobre el contenido y alcance de las políticas y estrategias económicas, sobre la manera en que éstas se formulan y aplican, y sobre las modalidades de interacción entre los agentes públicos y privados. Asi lo reconoce también la Declaración de San José cuando senala que "...la delensa y el fortalecimiento de la democracia representativa constituye la mejor garantía para la vigencia efecliva de lodos los derechos humanos."

En suma, la CEPAL ofrece ahora un marco analítico que integra modernización producliva, competitividad internacional, equidad, y sistemas políticos pluralistas y participativos. La principal conclusión de dicho análisis es que el crecimiento con equidad, en democracia, no sólo es deseable, sino lambién posible. Ello significa que también es posible responder tanto a los derechos de libertad individual, civil y politicos, como a los económicos, sociales y cullurales. 
Una consideración particular requiere la situación de los pueblos indígenas que constituyen una realidad poblacional y cullural esencial de la región. El enfoque sistémico del desarrollo que plantea la CEPAL supone protundas modificaciones a la siluación actual que enfrentan los pueblos indigenas en la región. Como bien sabemos, esos pueblos están fuertemente sobrerrepresentados en los indices de pobreza y de exclusión, en muchas partes carecen de reconocimiento juridico, de una legislación que los protege frente al despojo de sus recursos, de mecanismos que aseguren su participación en la resolución de los problemas que los afeclan, y del respelo por sus culturas e identidades propias.

América Latina y el Caribe para avanzar en su modernización productiva con equidad y una democracia más sólida requiere de una plena participación de los pueblos indígenas en el esluerzo productivo y en la dimensión ciudadana. Ello significa establecer una capacidad de la sociedad en su conjunto para reconocer a la vez la demanda de identidad de los pueblos indigenas junto a su demanda de desarrollo a través de caminos conjuntamente trazados que aseguren el respeto de sus derechos, el muluo reconocimiento, la permanencia y el enriquecimiento de su cultura y el desarrollo económico de una manera armónica y complementaria.

\section{III) Conclusiones}

Una primera conclusión que se puede recabar desde la óplica de América Latina y el Caribe en relación a los vínculos entre los derechos de libertad individual civil y política y los referidos al desarrollo económico, social y cullural se reliere a la desaparición de los motivos que existian en el pasado para separar el tralamiento de eslos lemas en los distintos foros de las Naciones Unidas. La consolidación de regimenes políticos pluralistas y participativos y el profundo significado que ha tenido para la región el final de la guerra fria viabilizan el enloque integral entre lo político, lo económico, lo social y lo cultural.

Ello permile acercar la práctica de los foros intergubernamentales a la letra de los instrumentos formales anles cilados. Más importante aún: se hace cargo de la realidad, dados los múlliples vínculos y efectos recíprocos que evidentemente existen entre el respeto de los derechos de libertad civiles y políticos de las personas y su derecho a acceder a un mayor nivel de bienestar material y espiritual. Se puede afirmar, en efeclo, que no es posible concebir el desarrollo económico sin el pleno respeto a los derechos humanos; al mismo tiempo, dilícilmenle se puede postular la defensa de los derechos humanos sin avances sostenibles en el liempo en maleria de bienestar económico y social. 
Una segunda conclusión es que a partir de este estrecho vínculo, la propuesta de CEPAL para enfrentar las tareas prioritarias del desarrollo en la región en los años 90 no es en ningún caso neutra frente al ejercicio de los derechos humanos en lodas sus dimensiones; los supone como un requisito para alcanzar dicho desarrollo.

Sólo el ejercicio de la plena ciudadania permitirá alcanzar de manera democrática y a través de la construcción participativa de consensos la cohesión social indispensable para alcanzar el desarrollo en las condiciones acluales de la economía mundial. Tal ejercicio de ciudadanía incluye los derechos civiles y políticos más clásicos, junto a los derechos económicos y sociales y los nuevos derechos relacionados con el medio ambiente, el consumo y la participación.

Una tercera conclusión se refiere a la necesidad de profundizar en la elaboración conceplual de los vínculos entre transiormación productiva con equidad y derechos humanos particularmente en sus dimensiones económicas y sociales, para establecer sus mutuas implicancias tanto para las propuestas de desarrollo como para el marco jurídico que dicho proceso requiere.

La declaración de San José establece al respecto diversos aspectos relacionados con la equidad, grupos vulnerables, y obsláculos socio económicos para el ejercicio de la ciudadania, sobre los cuales es necesario continuar trabajando.

Con ese fin la CEPAL se ha propuesto desarrollar una colaboración con el Instituto Interamericano de Derechos Humanos (I.I.D.H.) y otras instituciones relacionadas con los derechos humanos para avanzar tanto en el enfoque conceptual de estos temas como en la elaboración de propuestas que puedan ser útiles a los gobiernos de la región para hacer efectivo el cumplimiento de los derechos económicos y sociales en un contexto de crecimiento con equidad, democracia y sustenlabilidad. 